\title{
Redes heterogéneas del patrimonio. Los Casos del Centro histórico y el humedal Córdoba, Bogotá (Colombia) $^{1}$
}

Dolly Cristina Palacio ${ }^{2}$ y Maria Clara van der Hammen ${ }^{3}$ - Centro de Investigaciones sobre Dinámica Social, Facultad de Ciencias Sociales y Humanas - Universidad Externado de Colombia.

\section{Resumen}

Las políticas públicas sobre el patrimonio jugaron y aun juegan un papel importante en la construcción del Estado-nación y por lo tanto, forman parte del proyecto de actualización de la modernidad. Estas políticas, sustentadas en la aplicación de una supuesta "objetividad científica", construyen clasificaciones del patrimonio que además de autoritarias - pretenden instituir realidades patrimoniales al amparo de enunciados excluyentes.

Este estudio visualiza distintas redes sociales y socio-espaciales en dos lugarespatrimonio en Bogotá, a partir de las prácticas y representaciones de sus residentes, desde una perspectiva relacional. Partimos de considerar que tanto las personas como los espacios tienen un género y que las relaciones sociales y las relaciones espaciales se construyen mutuamente. Para entender estos dos "lugares-patrimonio" y su connotación local adoptamos la noción de red de lugar. Se toman medidas de centralidad para los residentes con respecto a los lugares, teniendo en cuenta sus formas de valorarlos y vivirlos. Los atributos principales para marcar las diferencias entre los residentes son su ubicación espacial en relación con los lugares-patrimonio y el uso que hacen del lugar sus residentes de acuerdo a su género. Estos tres atributos muestran distintos escenarios del lugar y presentan un panorama heterogéneo sobre las relaciones entre los residentes y los lugares-patrimonio. Con esto se muestra que la heterogeneidad es un aspecto importante para la formulación de estrategias de participación social en la planeación y gestión del patrimonio bajo el modelo de democracia participativa.

Palabras clave: patrimonio cultural y natural, redes sociales, género, análisis de lugar, Bogotá.

\section{Abstract}

Public policy about heritage has played an important role in the construction of national-states as part of the project of modernization. This project assumes a 'scientific objectivity' that defines categories and implements heritage settings, which results authoritarian as it excludes other visions.

\footnotetext{
${ }^{1}$ Producto de la investigación 'Usos, prácticas y representaciones del patrimonio natural y cultural de Bogotá' Financiada por COLCIENCIAS y la Universidad Externado de Colombia. Directora Adriana Parias. Co-investigadores Grupo Procesos Sociales, Territorios y Medio Ambiente CIDS - UEC.

2 dolly.palacio@uexternado.edu.co

3 maria.vanderhammen@uexternado.edu.co
} 
This study visualizes different social and social-spatial networks in two heritage sites of Bogotá, considering resident's social practices and representations from a relational perspective. We assume that people as well as places are gendered and that social and spatial relationships are mutually constructed. In order to understand these two heritage sites and their local realities, we adopt the notion of place-network. Particularly, we use centrality measurements by analyzing residents' use, value and experience of the heritage sites. The main attributes used to mark the differences amongst residents are spatial distance form the heritage sites and gender uses of the sites. As a result we obtain different scenarios of the sites that give evidence of heterogeneity in the relationship of residents with the places studied. This heterogeneity is a key issue to develop social participation strategies within the planning and management processes of heritage sites within participatory democracy models.

Key words: natural and cultural heritage, social networks, gender, place, Bogotá.

\section{I ntroducción}

El patrimonio ha sido recientemente objeto de un gran debate enmarcado en un contexto posmoderno que reconoce la diversidad y la presencia de múltiples identidades que cada vez hace más dificil pensar en un patrimonio colectivo que no considere esta diversidad y las formas de construir identidad. El patrimonio, en sus distintas concepciones, expresiones y contextos, ha sido entendido como una construcción social que fundamenta la identidad de una comunidad determinada, que tiene un carácter público y que está integrado por los bienes tangibles e intangibles que esa comunidad pretende preservar. En esta dirección, el patrimonio no sólo hace referencia a un pasado y a los monumentos históricos, sino que se encuentra anclado en la cotidianidad de las personas que comparten estos elementos, y a través de su gestión está relacionado con su futuro, a partir de la valoración simbólica (Tello 2002).

Sin embargo, tradicionalmente, el patrimonio ha sido un eje estructural muy importante en la construcción de la identidad cultural en los procesos de consolidación de los estados nacionales. El discurso y las prácticas que lo han construido han sido de tipo jurídico-político, así como un asunto técnico que le ha permitido a la clase dominante borrar marcas locales e imponer una lectura del pasado ajena a las vivencias del grueso de la población $\mathrm{y}$, por lo tanto, logra imponer la lectura de una clase sobre las otras (García Canclini, 1997; Tello, 2002). El patrimonio, como afirma García Canclini, “es el mejor lugar donde sobrevive la ideología de los sectores oligárquicos". Sin embargo, el patrimonio como un resultado de la materialización de los procesos de identificación social es valorado, vivido y por lo tanto apropiado por distintos actores de manera diferencial. Es así como para analizar el patrimonio García Canclini sugiere hacer uso del concepto de "capital cultural" de Pierre Bourdieu, puesto que éste permite entenderlo como un 
proceso social y simbólico que es susceptible de ser acumulado, reconvertido y rentable, y por lo tanto apropiado de forma desigual por los distintos actores.

En Colombia el patrimonio ha sido tradicionalmente definido desde el marco político-jurídico hasta años recientes en los que se ha logrado construir algunos espacios de participación social, con el objetivo de definir y hacer gestión conjunta del patrimonio (Palacio, 2006b). Es decir, se han venido creando unos espacios que permiten a los actores sociales construir un capital cultural desde una perspectiva propia.

En este artículo defendemos la importancia de acercarnos justamente a las representaciones y prácticas de los residentes de los dos lugares-patrimonio objeto de este estudio - el centro histórico de Bogotá y el humedal de Córdoba- así como a las dinámicas sociales locales que dan sustento a este capital cultural en los procesos de contrucción de unas políticas públicas del patrimonio a nivel distrital.

Las representaciones y las prácticas de los residentes de estos lugares - patrimonio construyen sus identidades en un proceso mutuo y dinámico. Una de las principales fuentes para la construcción de la identidad es la construcción mutua entre género y lugar. Asumiendo la perspectiva feminista y relacional de la geografía humanística, estamos de acuerdo con Linda McDowel (1999:54) en que "las personas, como los espacios, tienen un género y que las relaciones sociales y las relaciones espaciales se crean mutuamente". Es así como aquí adoptamos una perspectiva relacional para entender como se construyen los lugares-patrimonio por parte de sus residentes, adoptando la noción de red de lugar (Palacio, 2002; Palacio, Hurtado, Garavito, 2003) ${ }^{4}$ desde una perspectiva de género (McDowell, 1999). Esta forma de abordar el patrimonio es novedosa, puesto que primero parte de reconocer el papel relacional de los residentes en los procesos de configuración y definición de los lugares-patrimonio, identificando sus diferencias y heterogeneidades a partir de su construcción local, particularmente observando las diferencias de valoración y experiencia entre hombres y mujeres y sus relaciones socio-espaciales.

\footnotetext{
${ }^{4}$ Originalmente la noción que usaron estos autores fue lugar-red pero por su connotación anglosajona la cambiamos por redes de lugar para el uso del español.
} 
El reconocimiento del patrimonio, en este sentido, está estrechamente vinculado a la identidad. La construcción de una identidad colectiva tiene dos direcciones importantes, una dirigida a la cohesión interna del grupo, y otra que busca construir identidad a partir de la diferencia con los "otros", en este caso, a partir de las diferencias de género o cercanía con los lugares.

En este artículo se identifican particularmente las similitudes y diferencias entre los residentes con respecto a sus formas de valorar y vivir el lugar, mostrando las redes de los lugares-patrimonio a partir de tres dimensiones implicadas en la noción de capital cultural de Bourdieu: (i) las tensiones entre valoración y uso del patrimonio por parte de los residentes diferenciados por género, cercanía y saberes; (ii) las formas de construir las identidades con el lugar hacia fuera y hacia dentro. (iii) las formas de proyectar el lugar en relación con un patrimonio más ampliado en el contexto de la ciudad y en relación con el patrimonio declarado en el marco jurídico-político.

Los dos atributos principales para marcar las diferencias entre los residentes fueron su condición de cercanía o lejanía (centro-periferia) con respecto a cada lugarpatrimonio y el uso y valoración por género (grupos de hombres y mujeres). Estos dos atributos muestran distintos escenarios del lugar, de acuerdo al tipo de residente, puesto que presentan un panorama heterogéneo sobre las relaciones entre los residentes y el lugar. La heterogeneidad es un aspecto central para el diseño de las estrategias de participación social en los procesos de planeación y gestión del patrimonio. El resultado de este estudio es, entonces, un insumo importante para la definición de políticas y lineamientos en torno a la planeación y gestión participativa del patrimonio en la ciudad.

\section{Las redes de lugar ${ }^{5}$ una perspectiva relacional para entender y actuar en el patrimonio local}

Massey (1997) sostiene que el lugar no tiene características fijas, ni tiene siquiera bordes espaciales fijos. Los lugares, al ser definidos desde adentro y desde afuera, son necesariamente espacios de conflictos y contradicciones. El lugar no constituye entonces una única entidad, debe ser analizado como la consecuencia de una

\footnotetext{
${ }^{5}$ El concepto "redes de lugar" se utiliza aquí en sentido literal. No corresponde al concepto teórico "redes de lugares" introducido por Narciso Pizarro. Véase: Pizarro, N. (2002). Un nuevo enfoque sobre la equivalencia estructural: lugares y redes de lugares como herramientas para la teoría sociológica. Redes, Revista Hispana para el Análisis de Redes Sociales, 5 (2) [Nota del Editor].
} 
multiplicidad de intersecciones de flujos generalizados, de estructuras de poder, de discursos y de subjetividades.

En en este contexto el sujeto se define como un ser dinámico y descentrado. Según Thrift (1996), el sujeto no es mental, interior, primera persona, privado... Es un ser adaptable, dispuesto y flexible. El sujeto es corporal, espacial, sensorial, temporal, relacional... Esta condición relacional no sólo es concebida desde lo intersubjetivo sino también desde la relación del sujeto con las cosas de su entorno y localizado en el tiempo y en el espacio. Así es como el sujeto se construye a partir de su condición de género, que es resultado de una construcción cultural que también surge de la relación intersubjetiva, de las prácticas sociales y de la relación entre los sujetos y las cosas en contextos espacio-temporalmente definidos.

Por su parte, las cosas, en la mayoría de las teorías, están claramente diferenciadas de los sujetos, y los sujetos son siempre humanos. Latour (en Thrift, 1996) reconoce el poder de los objetos en las prácticas sociales y los define como vehículos de significado, superando la visión reduccionista de las cosas como simples "objetos pasivos", dispuestos para el consumo. Antes que todo, se reconoce que el mundo de los objetos está entrelazado con el de los sujetos. Los objetos son parte de la construcción de la subjetividad de los sujetos, y de sus capacidades y su desempeño, que se constituyen en lo que Bourdieu Ilama "capital cultural". Los objetos son reconocidos como entidades ecológicas, es decir, que establecen relaciones e influyen en el desarrollo de las interacciones que forman parte de las dinámicas del entorno en sentido amplio. Con respecto al contexto o la temporalidad y espacialidad de las relaciones entre los sujetos y las cosas, Thrift (1996) plantea que más que vivir en un espacio y un tiempo vivimos en el espaciotiempo vistos de manera práctica. Es decir, en cada parcela del espacio-tiempo los sujetos y los objetos se organizan en formas particulares que proveen orientaciones para la acción. En otras palabras, los contextos no son pasivos. En conclusión, podemos decir que todo espacio es antropológico, todo espacio es practicado, todo espacio es lugar.

El patrimonio, en este sentido, es practicado y representado por los sujetos en relación con los objetos del patrimonio en un espacio-tiempo específico y organizado en redes sociales y socio-espaciales que representan dinámicas delimitadas en el tiempo. Sujetos que son hombres y mujeres, y por consiguiente, 
sus diferentes roles y posiciones en contextos socioculturales específicos se construyen en forma diferente y con contenidos significativos particulares. Pero también hay construcciones de significados que son difusas y fluidas en los espacios locales, y por lo tanto son compartidas por mujeres y hombres. Por último, hay valoraciones remotas o difundidas por los medios masivos, como ideologías de centros culturales exógenos al local o los valores estéticos de las elites locales, difundidas por vía mediática; o bien ideas alternativas como el ambientalismo y el ecologismo, que juegan un papel en la construcción de significados de los residentes locales de los estudios de caso, que influyen en la resignificación y en las emergencias de nuevas prácticas e interpretaciones de los lugares.

\section{Metodología}

Para la realización de este estudio utilizamos la triangulación de métodos cualitativos y cuantitativos a partir del análisis de los resultados de 5 grupos focales ${ }^{6}$ y una encuesta que se hizo a una muestra de residentes de cada estudio de caso. Los resultados de estos dos métodos fueron analizados a partir el análisis de discurso para los grupos de discusión (Gross, 1996; Grudens-Schuck, Allen, Larson, 1999; Canales y Peinado, 1999) y el Análisis de Redes Sociales (ARS) (Wasserman y Faust, 1994; Hanneman, 2001; Forni, Siles y Barreiro 2004) para la encuesta (van der Hammen y Palacio, 2006).

Este artículo profundiza primordialmente en los resultados que se obtuvieron con la aplicación del ARS y sus posibilidades. Sin embargo, creemos profundamente en la integración metodológica entre los métodos cualitativos y cuantitativos (Bericat, 1998) para abordar el conocimiento de las relaciones sociales y socio-espaciales de una población, puesto que con ésta se enriquecen los resultados y se pueden ver aspectos que desde una sola perspectiva es imposible ver.

A partir de la encuesta que se aplicó a 503 residentes en sus hogares, 142 en el Humedal de Córdoba y 361 en el Centro Histórico ${ }^{7}$, se hizo el análisis de Redes Sociales, con el propósito de encontrar aspectos valorativos con indicadores relacionales. Es decir, visualizar los patrones de centralidad de los lugares de acuerdo al reporte de las prácticas y representaciones de los residentes sobre los

\footnotetext{
${ }^{6}$ Queremos agradecer de manera muy especial a todos los residentes del centro histórico y a los vecinos del humedal Córdoba que participaron en estos ejercicios aportando sus visiones y su saber.

7 La encuesta de la investigación tiene 109 preguntas que abordaban temáticas diversas en el interés de resolver preguntas mas amplias para el proyecto de investigación del cual hacen parte estos resultados.
} 
lugares y establecer la configuración de subgrupos de lugares centrales ofreciendo evidencias sobre los niveles de integración o dispersión social respecto al patrimonio. Para esta parte del estudio se utilizaron 10 preguntas, 5 de tipo atributivo (género, edad, nivel de educación, localizacion de la residencia por barrios y ocupación) y de tipo relacional (lugares que visita, lugares y prácticas que considera importantes, lugares donde llevaría a un extranjero, lugares que le enseñaría a un hijo y niño de su barrio).

Para cumplir el procesamiento de la información, se construyeron matrices de dos modos que configuraron los indicadores de centralidad de grado ${ }^{8}$ de los lugares y las prácticas patrimoniales, nombradas y valoradas por los residentes en las encuestas $^{9}$. Es muy interesante destacar que las categorías usadas para nombrar los lugares y las prácticas fueron establecidas por el encuestado-residente y en esta medida, podemos observar con gran detalle aquello que es valorado del lugar. Los indicadores de grado nodal se normalizaron a partir de una relación entre el número total de mujeres y hombres que respondieron a la pregunta. La graficación y visualización de las redes se hizo aplicando el programa UCINET VI (Borgatti, Everett y Freeman, 2002) ${ }^{10}$.

\section{Los lugares-patrimonio}

\subsection{La política patrimonial en Colombia}

Desde el siglo XIX se presenta una preocupación sistemática por la protección y conservación del patrimonio, centrado en objetos de valor histórico e íntimamente ligado al proyecto de modernidad del Estado-Nación colombiano y a la consolidación de una identidad nacional. Pero es realmente a lo largo del siglo XX que esta preocupación se traduce en un conjunto de normas. Este interés avanza de la mano con la aceptación de convenios y tratados internacionales, que permiten la declaración de bienes patrimoniales, mostrando una valoración primordial por lo histórico y monumental. En el desarrollo normativo del patrimonio en Colombia, prima el marco de los convenios internacionales y no se desarrolla una política propia que considere el patrimonio dentro de las particularidades del contexto

\footnotetext{
${ }^{8}$ La Centralidad de grado nodal $\mathrm{Cg}$, está definida como el número de vínculos relacionado con un nodo dado ni. En términos prácticos, se trata de la suma de las entradas de las columnas (popularidad) y de las filas (expansión).

9 Para determinar esta valoración se solicitó a los encuestados nombrar en orden de importancia 5 lugares o prácticas de su entorno. Estos fueron valorados en las matrices de acuerdo al orden de importancia dada por el encuestado: así, el lugar o la práctica nombrada en el primer puesto recibe 5 puntos, el del segundo 4 puntos, el tercero 3 puntos, el cuarto 2 puntos y el quinto tan sólo 1 punto.

${ }^{10}$ Gracias a Rafael Hurtado y Shirley Gómez por su participación en el análisis numérico y la graficación.
} 
nacional (Garavito, 2006). En este contexto, en 1963 se declara, entre otros, el centro histórico de Bogotá como patrimonio, y en 1977 los cerros orientales se declaran Area de Reserva Forestal Protectora.

La Constitución Política de 1991 introduce unos cambios importantes como la instauración de un modelo de democracia participativa, el reconocimiento de una identidad multicultural y una reforma de la administración pública hacia un sistema decentralizado, lo que en conjunto cambia el marco para la política del patrimonio. De esta manera, se abre la posibilidad de una mayor participación de sectores amplios de la sociedad en la construcción de esta política, teniendo en cuenta la diversidad de identidades y patrimonios de grupos específicos, así como establece las bases para que las entidades territoriales locales puedan desarrollar estrategias propias para la identificación y gestión del patrimonio.

En este sentido, El Plan de Ordenamiento Territorial de Bogotá (Dec. 619 de 2000) se convierte en una herramienta para la gestión de su patrimonio, donde se incluyen listados de bienes de interés cultural y se asume la figura de estructura ecológica principal que permite incluir la dimensión ecológica a la planeación urbana. En este contexto, en el año 2000 se declara entre otros al Barrio Niza Sur bajo la categoría de 'conjunto de vivienda en serie' como patrimonio cultural del distrito. En el año 2001 se declaran los pocos humedales que aún quedan dentro del perímetro urbano como reservas ambientales naturales de interés público y patrimonio ecológico. A pesar de estos avances, se puede decir que no se ha consolidado una política del patrimonio tanto para la ciudad como a nivel nacional, y especialmente aún falta mucho por desarrollar en cuanto a las posibilidades que ofrece el modelo de democracia participativa.

\subsection{Los estudios de caso}

La investigación de la cual aquí se presentan algunos resultados se llevó a cabo en Bogotá, Colombia. Esta ciudad se encuentra ubicada en el altiplano andino a una altura de $2.600 \mathrm{msnm}$, rodeado por cerros que alcanzan una altura hasta de 3.200 msnm. La sabana ha sufrido desde la última glaciación (hace 20.000 años) una paulatina desecación pasando de un paisaje de amplias zonas lacustres y anegadas, es decir, lagunas y humedales a zonas más secas. Este proceso que se debe a cambios climáticos, ha sido acelerado por la acción humana, especialmente desde la llegada de los españoles quienes fundan la ciudad en este lugar sobre un asentamiento indígena, aprovechando las múltiples corrientes de agua y el 
resguardo de los cerros que protegen el lugar de los vientos. El asentamiento fue diseñado siguiendo el típico patrón de damado impuesto por la colonia.

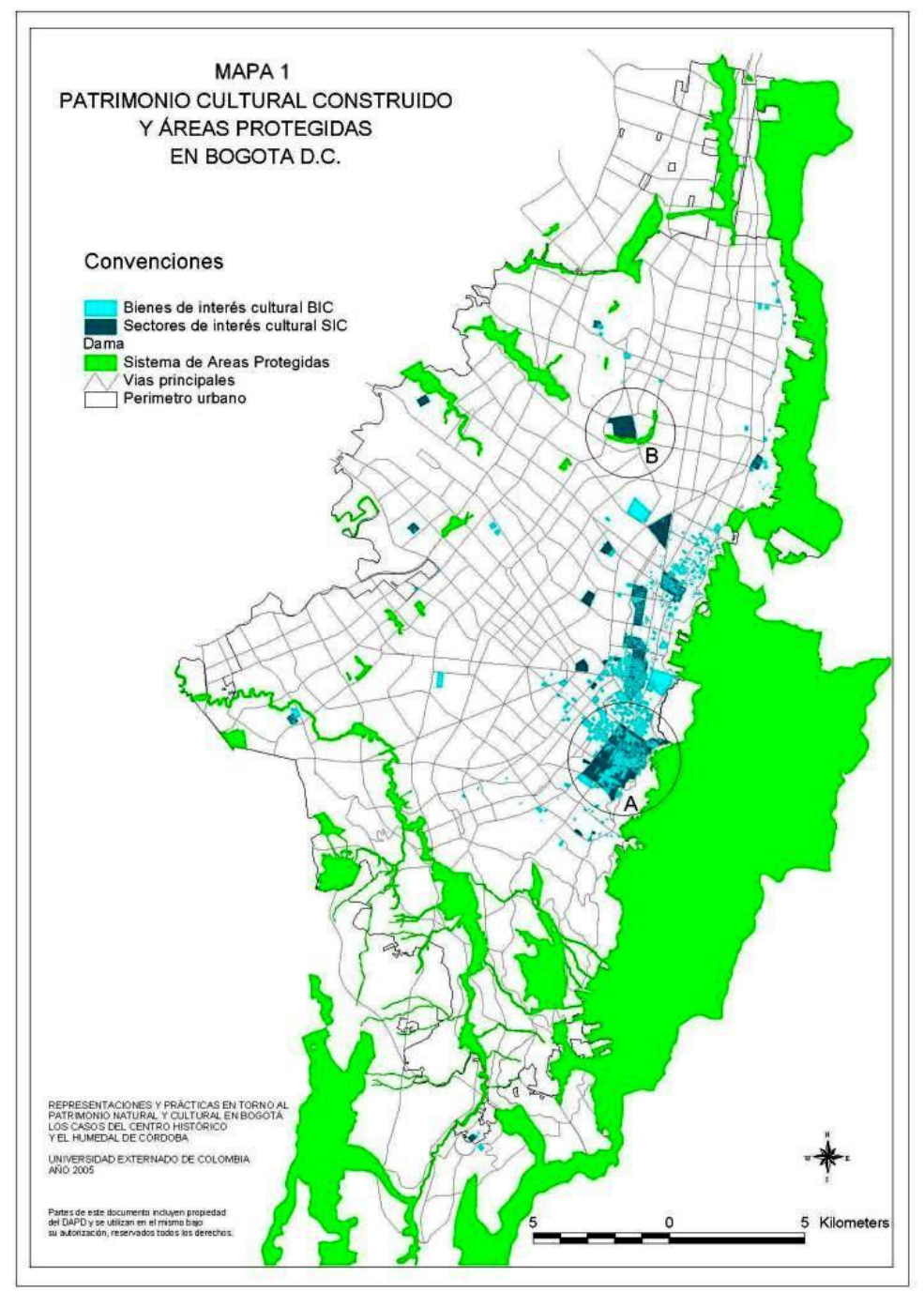

I lustración 1. Patrimonio cultural y áreas protegidas en Bogotá D.C.

Fuente: Jeffer Chaparro (2006). Construcción a partir de datos del Departamento Administrativo de Planeación Distrital.

La ciudad mostró un lento crecimiento en los primeros siglos después de su fundación, hasta que en el siglo XX se ve enfrentada, como todas las ciudades latinoamericanas, a un acelerado crecimiento poblacional que obligó a asumir una planeación urbana moderna, expandiendo las redes de servicio público y las vías y ocupando las zonas rurales aledañas. Para este fin se desecaron numerosos terrenos pantanosos, que de hecho eran los más económicos por su bajo valor para uso agropecuario. De esta manera se pasó a reducir el área de humedales de 50.000 hectáreas a mediados de siglo XX a 700 hectáreas, ubicadas en la actualidad dentro del perímetro urbano. 
Para la investigación se seleccionaron dos lugares-patrimonio en Bogotá que reunieran tanto elementos reconocidos como patrimonio natural y cultural. El primer caso es el centro histórico y los cerros orientales aledaños, el segundo el humedál de Córdoba y el barrio Niza Sur contiguo.

\subsubsection{El centro histórico y los cerros aledaños}

El centro histórico o antigua ciudad ha sido objeto de múltiples transformaciones. Entre ellas se pueden destacar la reforma, ampliación o reemplazo de las edificaciones coloniales con edificios de estilo republicano, y luego modernos; la ampliación de las vías y la contrucción de zonas de aparcamiento para la creciente actividad institucional y cultural. Hacia la mitad del siglo XX, las clases altas abandonan el centro estableciendo su residencia en zonas localizadas al norte de la ciudad, mientras que hacia el sur se establecen barrios populares, consolidándose de esta manera una segregación socio-espacial marcada (Parias, 2006). El centro muestra, durante un buen período un proceso de deterioro urbano y sólo hacia los años noventa surge una preocupación estatal por su recuperación y un nuevo interés por parte de familias de estrato medio, por esta zona a partir de carácter patrimonial, lo que hace que el centro vuelva a tener una conformación social más diversa (Párias, 2006; Chaparro 2006).

En este lugar se encuentran numerosas iglesias, antiguos claustros, teatros, bibliotecas y edificios que albergan entidades gubernamentales (El Capitolio, El Palacio Presidencial, La Vice-presidencia, los Ministerios, etcétera) que de manera particular han sido declarados bienes de interés cultural. Este lugar, en el presente, cumple funciones político-administrativas y culturales y ha dejado de ser el centro financiero y comercial. Los cerros orientales tuvieron en épocas precolombinas un carácter sagrado para el pueblo Muisca que ocupaba este territorio. Los españoles en su afan por las riquezas y lograr la evangelización saquearon los santuarios, remplazándolos por santuarios cristianos en las cimas de los cerros que hoy se han convertido en importantes lugares de peregrinación para los Bogotanos y visitantes. Esta zona rural ha cumplido funciones de despensa de la ciudad (leña y productos agropecuarios) y de fuente de agua para el acueducto de la ciudad.

El centro histórico hoy es objeto de planeación local, expresado en el "plan centro" que fue formulado por la administración distrital. Este plan ha provocado mucho debate por su importancia global para la ciudad y los múltiples intereses que ahí confluyen. A persar de su importancia, los habitantes del sector han tenido un papel modesto en su definición y gestión. Por otra parte, los cerros orientales que 
desde la perspectiva de los pobladores rurales y habitantes del centro reúne varias funciones y valores patrimoniales (religiosos, culturales, ecológicos) son definidos por la administración distrital principalmente como productores de agua, restringiendo su uso, lo que afecta a los pobladores tradicionales de los cerros y a su vez toca importantes intereses económicos de los urbanizadores, quienes proponen la expansión urbana hacia esta zona.

\subsubsection{El humedal de Córdoba y el barrio Niza Sur}

El humedal de Córdoba se encuentra en una zona que hasta los años sesenta era parte de la zona rural aledaña a Bogotá. Tierras poco fértiles que por su carácter de inundables, tenían poco valor. Era una zona utilizada principalmente para la ganadería y algunos cultivos como el maíz y la papa. El río que alimenta este humedal era zona de pesca de algunas especies nativas por los pobladores antiguos, descendientes de los Muiscas. En los años sesenta en este lugar se construyó un proyecto de vivienda en serie destinado a familias jóvenes de profesionales estatales. Este barrio quedaba lejos de la ciudad y sufría de todas las incomodidades del aislamiento; falta de vías y medios de transporte y ausencia de comercio. Esto creó en los habitantes lazos de solidaridad y una identidad fuerte. Aún en la actualidad se mantiene un núcleo de los habitantes pioneros. El barrio quedaba aledaño a una zona inundable, espacio de recreación especialmente para los niños que encontraban ahí un lugar de juego lleno de posibilidades. Con la expansión urbana, el humedal se convirtió en un caño maloliente, receptor de aguas negras y en botadero de basura. Algunos vecinos trataron de mitigar este proceso mediante la siembra de árboles, pero en general se consideraba un 'estorbo' y se llegaron a formular tanto desde los habitantes como desde la administración distrital todo tipo de proyectos, como desecar este espacio, o convertirlo en una zona de recreación acuática pública. Poco a poco, esta zona quedó absorbida por la ciudad y en la actualidad este barrrio es una isla verde con amplios antejardines y parques y está rodeada por importantes vías, barrios residenciales y centros comerciales (Chaparro, 2006; Hammen van der, 2006; Rodriguez, 2006).

En los años noventa, sectores sociales preocupados por la ecología se preocuparon por los relictos de humedales que quedaron dentro de la ciudad, estableciendo alianzas con los habitantes locales para tratar de recuperar y defender este espacio natural con importantes funciones reguladoras para el sistema hídrico de la ciudad, así como por su biodiversidad, especialmente de aves (Palacio, Hurtado, Garavito, 2003). Esta acción ambiental redundó en la normatividad y el desarrollo de una 
política pública que busca hacer conservación de los humedales del Distrito (Palacio, 2006a). .

La administración distrital y sus instituciones de gestión han propuesto distintos planes de gestión de esta área que han generado mucha controversia. Los ambientalistas y pobladores locales han aprovechado los espacios participativos para tener ingerencia sobre la protección y gestión de este lugar y fueron fundamentales para el reconocimiento del valor patrimonial. De otra parte, la definición del barrio Niza Sur como bien de interés cultural tuvo menos participación social, pero se debe al interés de sus habitantes ya organizados alrededor de la defensa del humedal que han encontrado en esta figura un respaldo para sus esfuerzos de mantener el carácter residencial del barrio.

En síntesis, se puede decir que estos lugares-patrimonio muestran una gran dinámica y controversia sobe los valores que deberían primar ahí y qué tipo de patrimonio pueden representar.

\section{Las redes de lugar y sus patrones de uso y valoración}

La primera dimensión de este análisis sobre las tensiones entre valoración y uso del patrimonio por parte de los residentes diferenciados por género, cercanía y saberes se presentará para cada uno de los lugares-patrimonio estudiados.

\subsection{El Centro Histórico}

La lista de sitios y prácticas de interés para los residentes tanto desde el punto de vista de sus prácticas cotidianas como de su valoración patrimonial muestra una alta heterogeneidad. En primer lugar la lista que se obtuvo de 361 residentes en el centro muestra para las prácticas cerca de 150 elementos y para la valoración del patrimonio ( 3 matrices) oscila entre 160 y 270 elementos de acuerdo a la pregunta). Lo que denota una alta variedad de sitios y prácticas identificadas por los residentes en su escala de valoración por un lado y una diferencia entre lo valorado y lo que es visitado y apropiado en las prácticas cotidianas. De igual forma encontramos sitios que son nombrados desde una visión muy local e individual. En este sentido, podriamos hablar de una visión del patrimonio difusa que aunque permite identificar centralidades emblemáticas tambien muestra una gran variedad de sitios y prácticas muy localizadas. En síntesis, no hay un consenso general entre los residentes sobre lo que es valorado, además lo que se valora no es necesariamente lo que se usa con mayor frecuencia. Es evidente el subgrupo de sitios valorados que se relaciona con sitios emblemáticos por su carácter histórico y 
la importancia de los museos y las bibliotecas que se asocian a esta misma visión compartida (subgrupo: Plaza de Bolivar, Museo del oro, Museo Nacional y Biblioteca Luis Angel Arango).

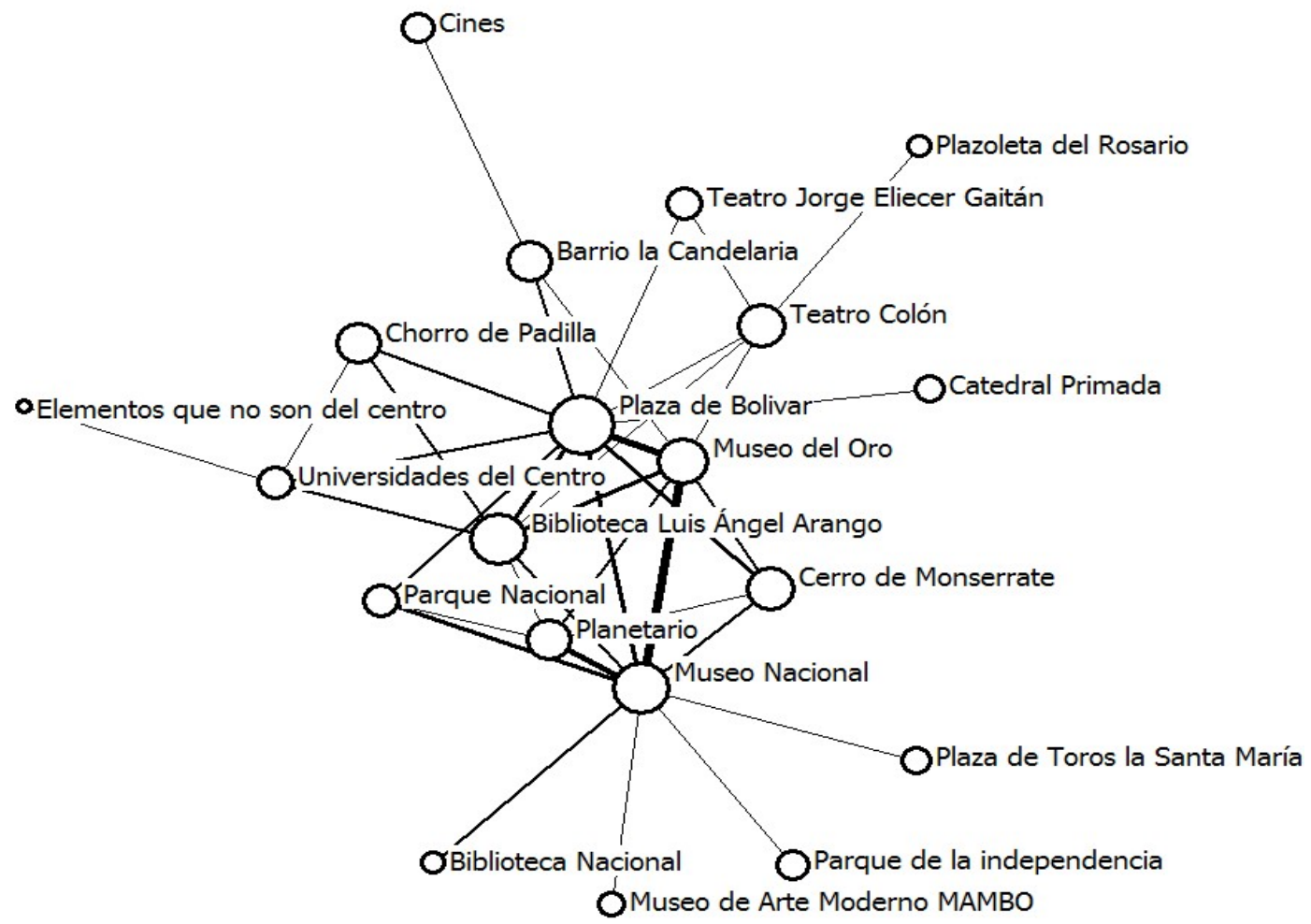

Grafo 1. Valoración de los sitios del centro histórico por parte de sus residentes.

Los nodos son los lugares. El tamaño de los nodos es proporcional a la centralidad de grado de los lugares. Los vínculos entre actores se construyen tomando las coincidencias en las actividades de los habitantes, en cuanto se relacionen con un lugar o elemento urbano; se toman aquellos mayores o iguales a 10. El espesor de las líneas es proporcional al valor de los vínculos.

Podemos entonces concluir que para sus residentes el centro histórico es ante todo el lugar donde realizan sus actividades cotidianas y desarrollan su vida. En este sentido podemos ver que los sitios más visitados se vínculan entre sí en cuatro subgrupos. El primero podríamos verlo como un cluster con una connotación de espacio público para su movilidad y esparcimiento cuyo centro es la Plaza de Bolivar. El segundo es un subconjunto que articula sitios de interés cultural, donde aparecen teatros, cinces, museos y cuyo centro es la Biblioteca Luis Angel Arango. El tercero es un subgrupo de tipo comercial y el cuarto un subgrupo donde se aglutinan sitios de interés natural con algunos de interés cultural. 


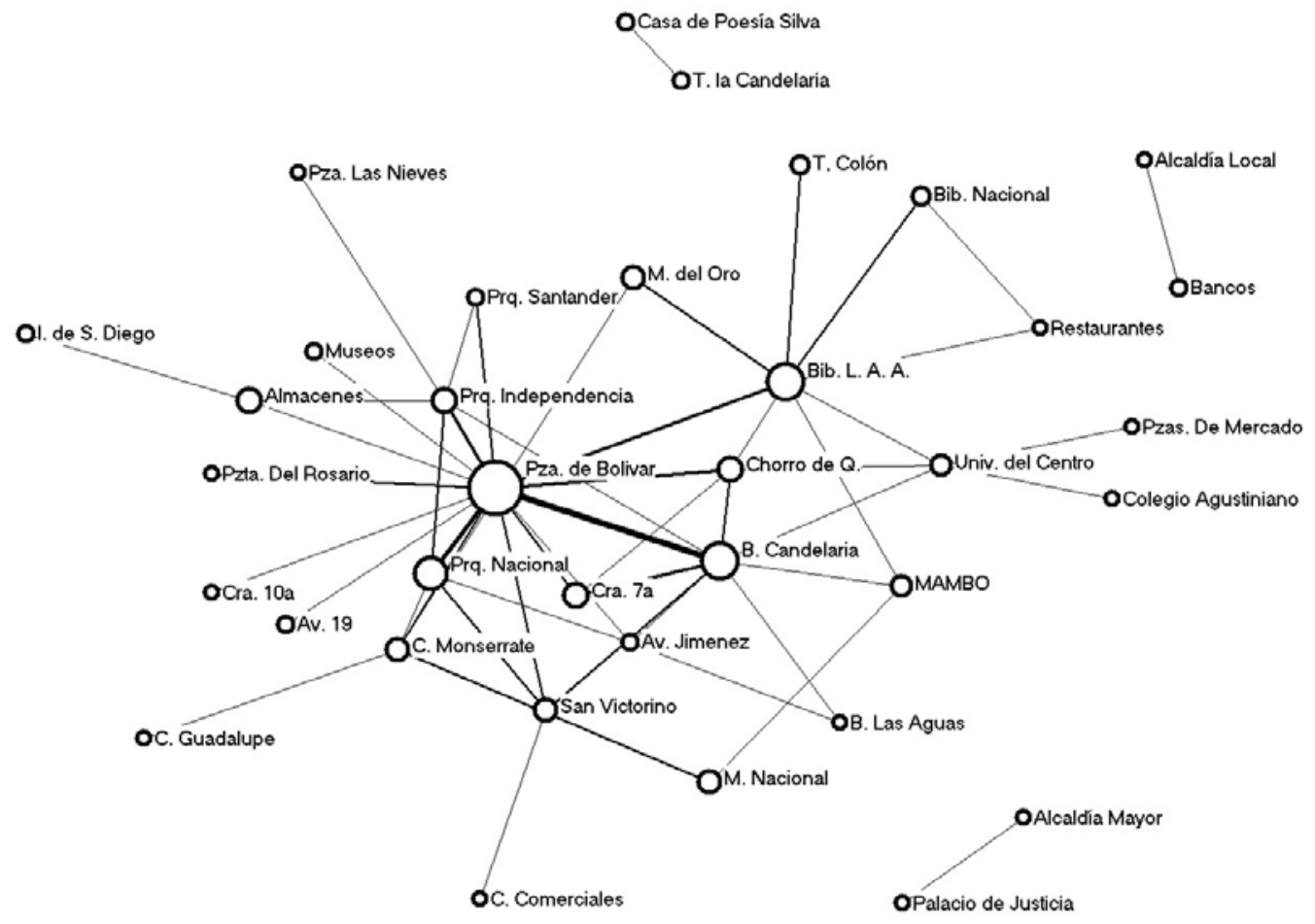

Grafo 2. Sitios más visitados por los residentes del centro

Los nodos son los lugares. El tamaño de los nodos es proporcional a la centralidad de grado de los lugares. Los vínculos entre actores se construyen tomando las coincidencias en las actividades de los habitantes, en cuanto se relacionen con un lugar o elemento urbano; se toman aquellos mayores o iguales a 3 . El espesor de las líneas es proporcional al valor de los vínculos.

Con respecto a la cercanía de residencia y la localización de los lugares altamente valorados vemos que sólo la Plaza de Bolivar muestra una integración de residentes cercanos y lejanos. Otros bienes muestran subgrupos que se relacionan más con el lugar por su cercanía espacial que por la valoración que los residentes localmente hacen de ellos. En síntesis, entre los lugares importantes para la cotidianidad de los residentes se pudo distinguir entre lugares de patrimonio muy local, es decir, un patrimonio barrial, y un patrimonio más global reconocido por grupos amplios. 


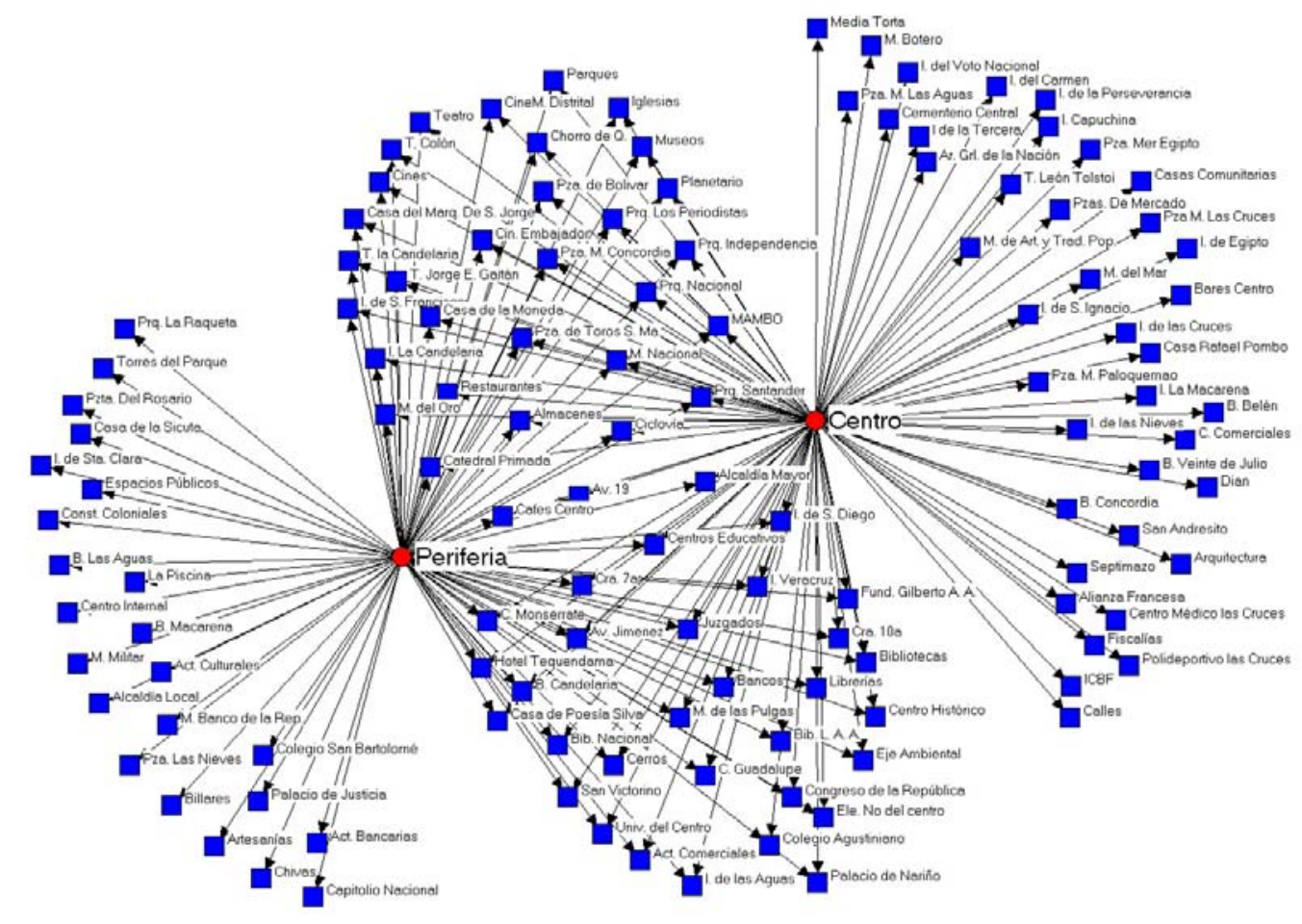

Grafo 3. Sitios más visitados por sus residentes (diferenciando atributos de cercanía: centro-periferia) según barrio que habitan. Los vínculos son las visitas de los residentes a los lugares.

En cuanto a diferencias entre hombres y mujeres se pudo ver una diferencia de género en cuanto a las representaciones y prácticas, resultando especialmente significativo que las mujeres muestran una mayor valoración con el patrimonio natural pero los hombres muestran mayor uso del mismo.

Un aspecto que llama mucho la atención es que la religión y las iglesias no aparecen en las distintas expresiones de valoración del patrimonio; sin duda un reflejo de la secularización de la sociedad. Es cierto que en el centro existen muchas iglesias importantes, pero ninguna de ellas es percibida tan importante como para que exista un consenso sobre su centralidad en la valoración. Por ejemplo, la catedral Primada, en ese sentido, parece casi ausente en la valoración de los habitantes del centro. Aún como conjunto, las iglesias ocupan un lugar muy modesto en la valoración: después de los museos, las plazas y parques, y los teatros. 


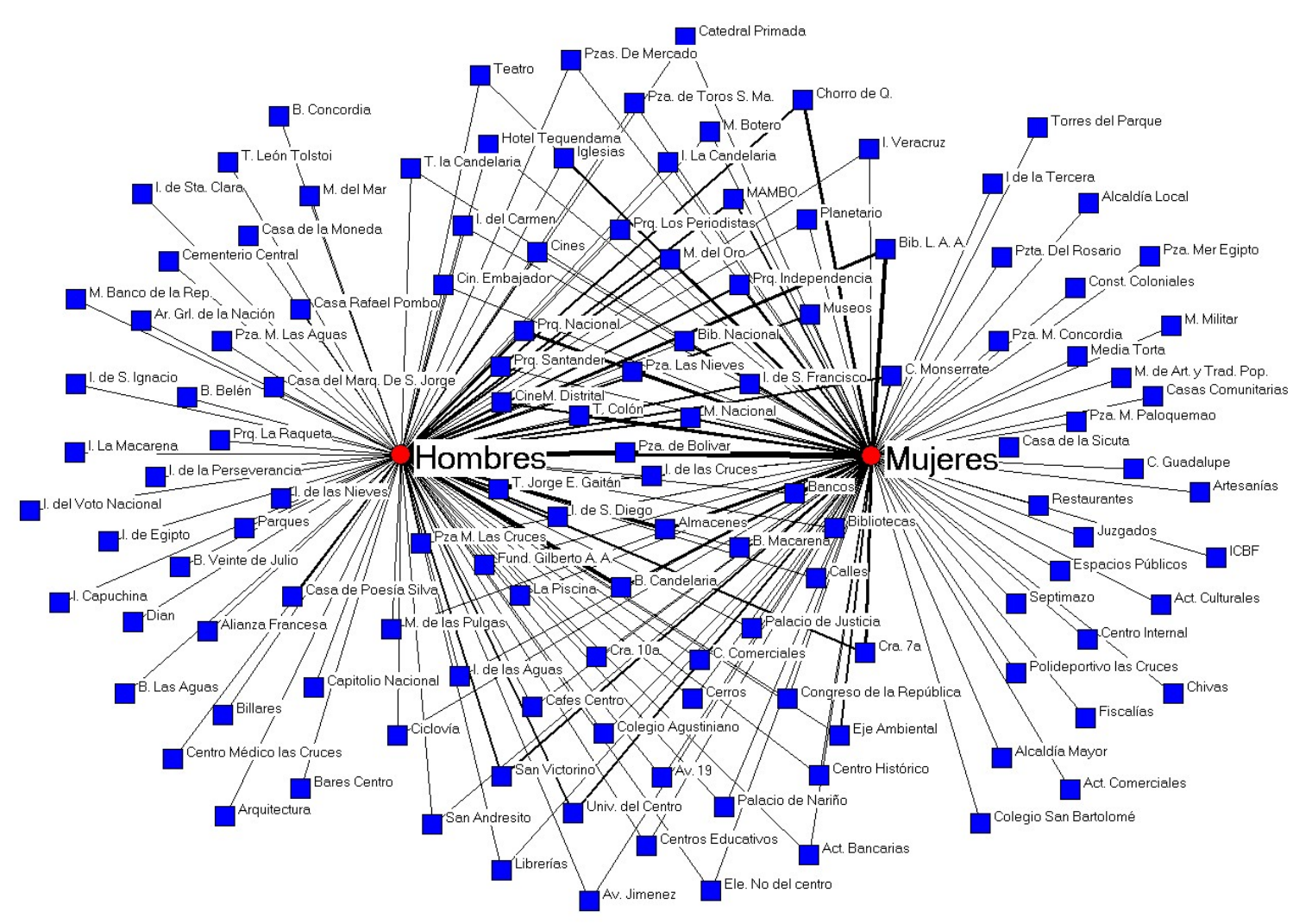

Grafo 4. Sitios del centro más frecuentados por hombres y mujeres.

Los vínculos son las visitas de los residentes a los lugares. El espesor de las líneas es proporcional al valor de los vínculos (ocurrencia de residentes hombres o mujeres en el sitio).

Para resumir se puede decir que para los residentes del centro histórico no coincide completamente lo valorado o patrimonial con los espacios incorporados en las prácticas cotidianas. El valor simbólico puede llegar a desligarse del valor de uso. En el centro histórico se han consolidado una serie de discursos generalizados que están apropiados por los residentes y por lo tanto, su valoración no necesariamente pasa por un proceso valorativo a través de las prácticas cotidianas.

\subsection{El humedal Córdoba}

Este lugar patrimonial representa para sus residentes un conjunto de elementos valiosos, aunque en menor cantidad que la registrada para el centro, entre los que sobresalen algunos elementos emblemáticos como el humedal mismo, los parques de la zona, y el centro comercial Bulevar Niza. El lugar se valora en primer lugar por su patrimonio natural, mientras el barrio Niza Sur parecería tener un valor más ligado al patrimonio barrial para sus propios residentes, mostrando una valoración menor por el resto de los residentes de la zona. 


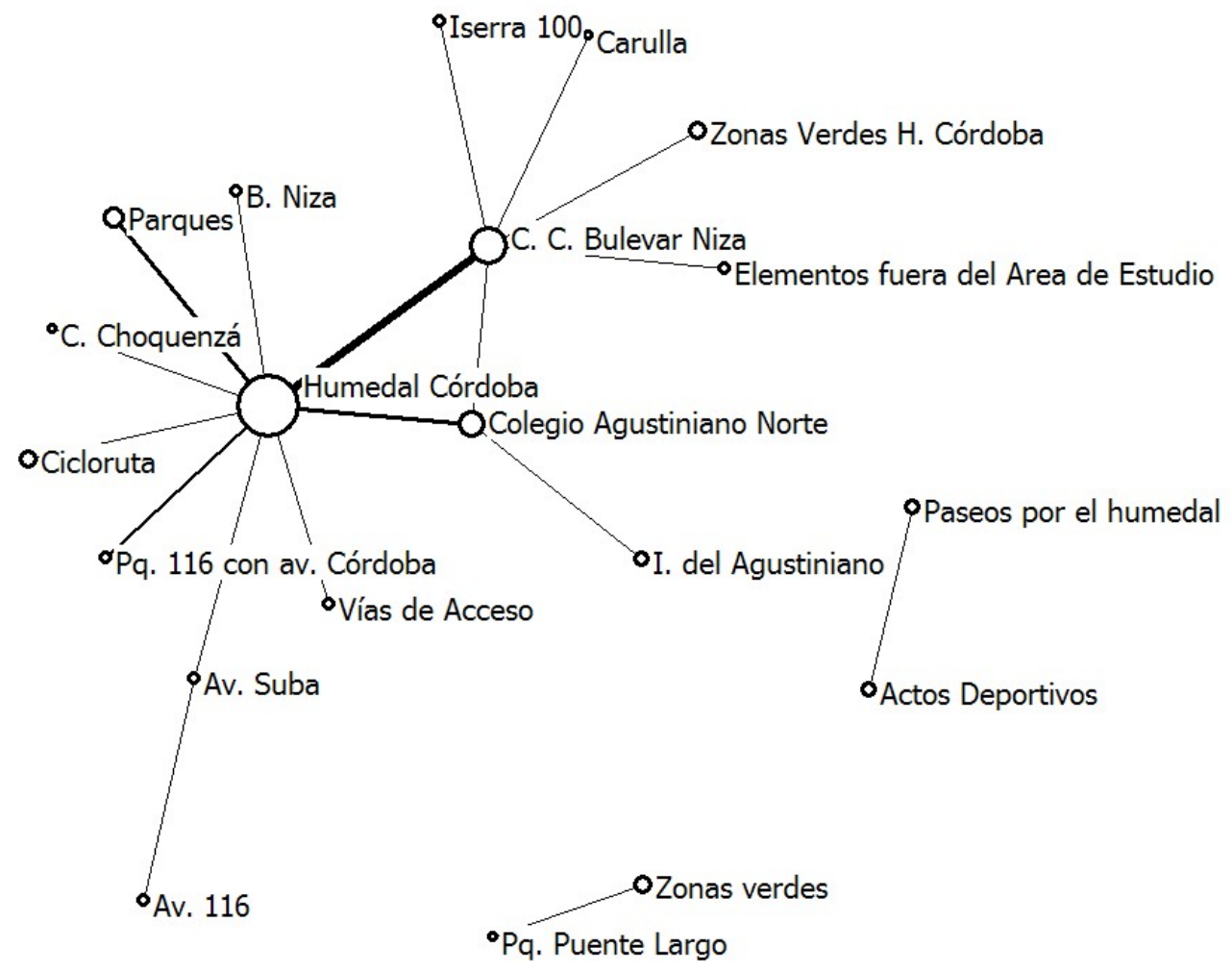

Grafo 5. Valoración de los sitios por parte de los residentes vecinos al humedal

Los nodos son los lugares. El tamaño de los nodos es proporcional a la centralidad de grado de los lugares. Los vínculos entre actores se construyen tomando las coincidencias en las actividades de los residentes, en cuanto se relacionen con un lugar o elemento urbano. El espesor de las líneas es proporcional al valor de los vínculos.

En este lugar, los sitios valorados son al mismo tiempo los sitios más visitados de manera cotidiana, es decir donde mayor número de residentes coinciden, existiendo por un lado un conjunto de sitios o espacios públicos verdes, en especial el humedal de Córdoba, que articula a grupos de residentes y a un conjunto de lugares comerciales agrupados alrededor del centro comercial Bulevar Niza. Entre los sitios importantes para la cotidianedad de los residentes se pudo distinguir entre lugares de patrimonio muy local, es decir un patrimonio barrial y un patrimonio más amplio: El humedal. 


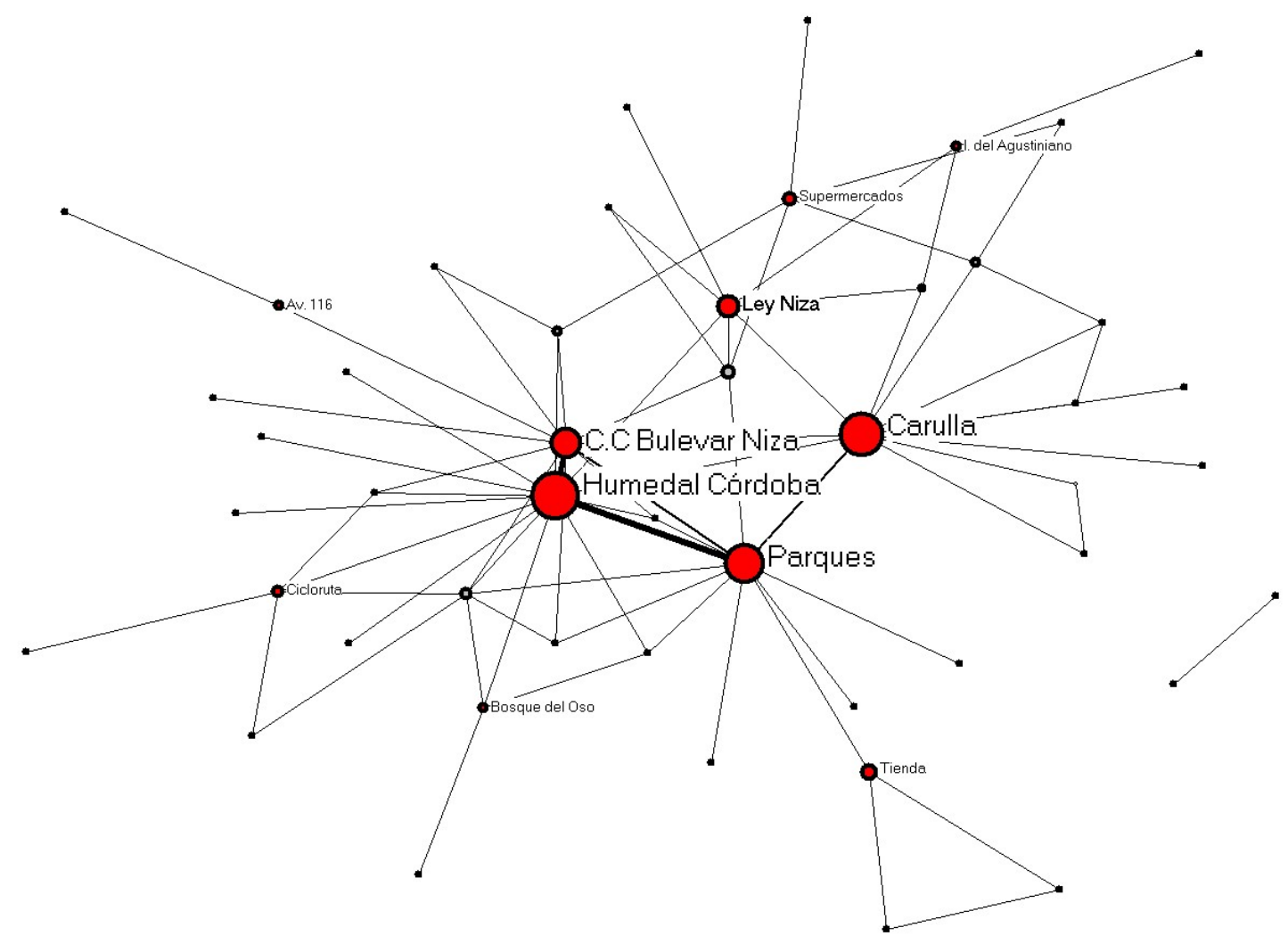

Grafo 6. Sitios más visitados por los residentes vecinos del Humedal.

Los nodos son los lugares. El tamaño de los nodos es proporcional a la centralidad de intermediación de los lugares. Los nodos rojos (con rótulo) son puntos de corte del grafo, es decir que si se quita cualquiera de ellos en un grafo éste deja de ser conexo. Los vínculos entre actores se construyen tomando las coincidencias en las actividades de los habitantes, en cuanto se relacionen con un lugar o elemento urbano. El espesor de las líneas es proporcional al valor de los vínculos.

También se pudo ver una diferencia de género en cuanto a las representaciones y prácticas, resultando especialmente significativo que las mujeres muestran una mayor cercanía con el patrimonio natural.

En la zona del Humedal, el número de iglesias es mucho más bajo que en el centro, los habitantes nombran 7 iglesias. Aquí tampoco aparecen las iglesias en los elementos más valorados por los habitantes; ellas aparecen después del humedal, los parques, los centros comerciales y hasta después de elementos como el Colegio Agustiniano o los clubes sociales ubicados en esta zona, sitios restringidos en su acceso directo para la mayoría de los habitantes. 


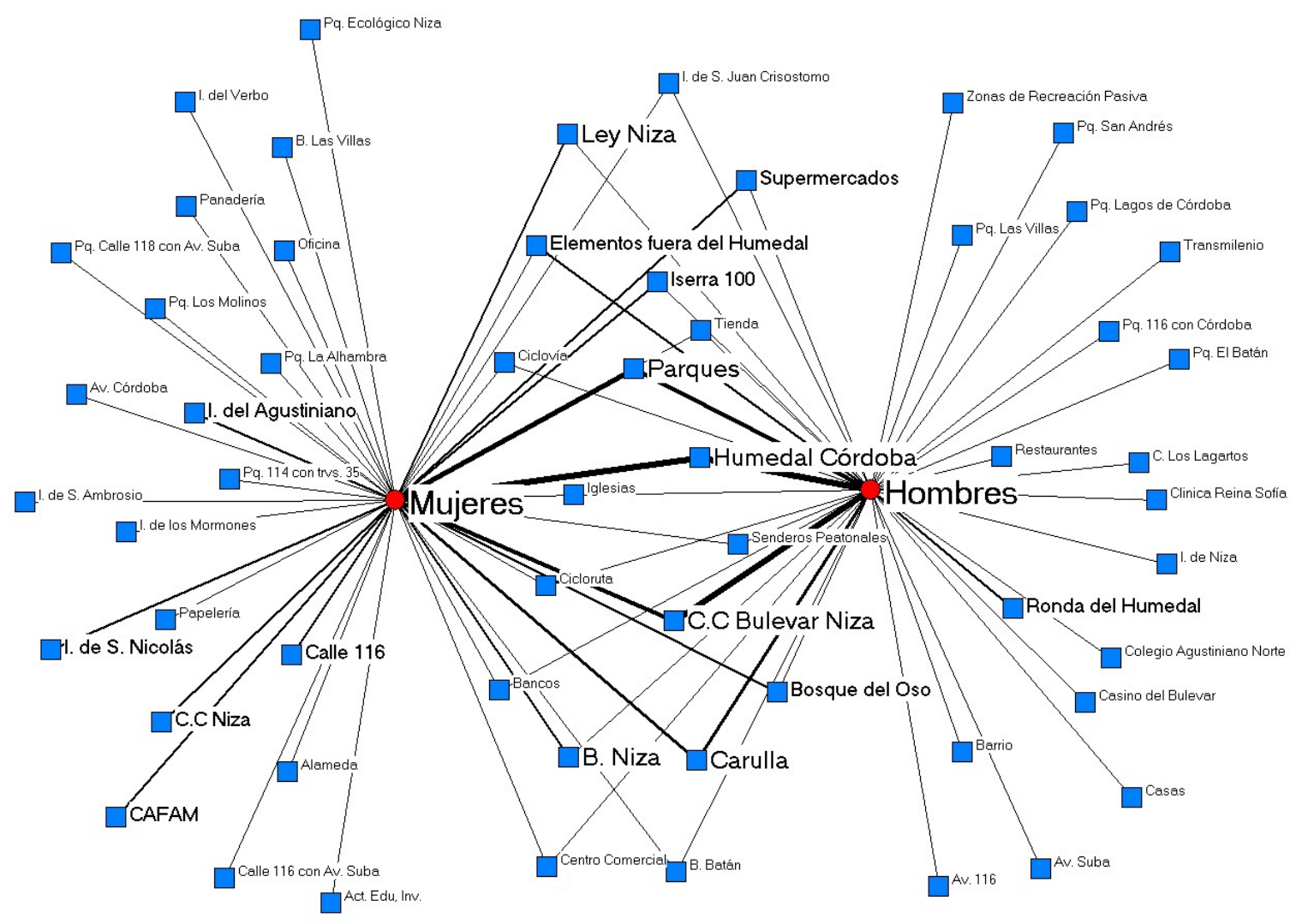

Grafo 7. Sitios más visitados por hombres y mujeres.

Los vínculos son las visitas de los residentes a los lugares. El espesor de las líneas es proporcional al valor de los vínculos. Los lugares rotulados son los que son visitados más frecuentemente (por lo menos 15 residentes manifiestan visitarlos).

En síntesis se puede decir que para el humedal de Córdoba, los lugares considerados importantes coinciden con aquellos que están involucrados en las prácticas cotidianas de los residentes. Podríamos decir que aquí existe una identificación entre lo valorado y por lo tanto sujeto a ser patrimonio, y lo apropiado en el uso cotidiano. El discurso sobre los valores patrimoniales de este lugar es apenas emergente, y por lo tanto, esos valores no han sido incorporados de manera generalizada por los residentes. Por ello, la valoración se presenta a través de las prácticas.

\section{Construcción de identidades a partir del lugar}

En cuanto a la segunda dimensión de este estudio - los procesos de construcción de las identidades-, se observa coincidencia en torno a algunos elementos emblemáticos de cada lugar-patrimonio. En este proceso, el capital cultural se diversifica sosteniéndose en distintas prácticas como el turismo y la educación, mostrando distintos valores. En la valoración de los lugares por su importancia turística o educativa muestran cómo está construida su identidad con el lugar a 
través de una red de elementos particulares, que dan cuenta del contenido significativo que representa para ellos.

Se pueden encontrar múltiples expresiones de lo que se considera patrimonio. No es lo mismo percibir, de manera global, como importante un lugar o una práctica, que pensar su contribución en la construcción de una identidad hacia fuera, lo que, en otras palabras, nos gustaría mostrar para el turismo. La percepción del lugar va a variar si pensamos en el valor educativo y en lo que se considera debe transmitirse a las siguientes generaciones; otra será su valoración desde el papel que juega en la cotidianidad.

\begin{tabular}{|r|l|r|r|r|}
\hline & Lugares & Mujeres & Hombres & Grado nodal \\
\hline 1 & Cerro de Monserrate & 313 & 264 & 577 \\
\hline 2 & Capitolio Nacional & 260 & 229 & 489 \\
\hline 3 & Museo del Oro & 210 & 255 & 465 \\
\hline 4 & Plaza de Bolívar & 233 & 232 & 465 \\
\hline 5 & Museo Nacional & 130 & 147 & 277 \\
\hline 6 & Museos en general & 62 & 94 & 156 \\
\hline 7 & Chorro de Quevedo & 66 & 71 & 137 \\
\hline 8 & Teatro Colón & 71 & 55 & 126 \\
\hline 9 & Quinta de Bolívar & 57 & 67 & 124 \\
\hline 10 & Biblioteca Luís Ángel Arango & 61 & 58 & 119 \\
\hline
\end{tabular}

Tabla 1. Lugares del centro histórico con mayor valor turístico, diferenciado por género. Fuente: encuesta de la investigación. Los valores están normalizados, es decir el valor es relativo en relación al número de respuestas y encuestados por sexo.

En el centro, el elemento más valorado es el Museo Nacional, un lugar que se percibe como importante porque ahí se conserva la historia, la 'grandeza' de la nación. Otro lugar considerado importante es la Biblioteca Luis Ángel Arango, sitio en donde se conserva el patrimonio documental. A la hora de mostrar el centro a un extranjero, no se piensa llevarlo a un lugar como la biblioteca sino que se buscan elementos que pudieran impresionar, como el cerro de Monserrate, un lugar imponente desde donde se puede observar una imagen global de la inmensa ciudad. El Capitolio es el siguiente elemento a mostrar, tal vez por su monumentalidad y como expresión del poder político, al igual que el Museo de Oro, lugar donde se conservan riquezas de la nación. A la hora de enseñar el centro a los hijos, aparece en primer lugar el Museo de Oro, donde se expone la riqueza en oro, se ilustra sobre el desarrollo cultural de las culturas precolombinas y por lo tanto, pareciera percibirse el pasado indígena como el fundamento de la identidad cultural. 


\begin{tabular}{|r|l|r|r|r|}
\hline & Lugares o prácticas & \multicolumn{1}{|l|}{ Mujeres } & \multicolumn{1}{l|}{ Hombres } & \multicolumn{1}{l|}{ Grado nodal } \\
\hline 1 & Museo del Oro & 235 & 243 & 478 \\
\hline 2 & laza de Bolívar & 174 & 206 & 380 \\
\hline 3 & Museo Nacional & 155 & 179 & 234 \\
\hline 4 & Cerro de Monserrate & 158 & 161 & 319 \\
\hline 5 & Biblioteca Luís Ángel Arango & 139 & 114 & 253 \\
\hline 6 & Planetario Distrital & 109 & 124 & 233 \\
\hline 7 & Barrio La Candelaria & 115 & 86 & 201 \\
\hline 8 & Museos en general & 112 & 80 & 192 \\
\hline 9 & Parque Nacional & 121 & 61 & 182 \\
\hline 10 & Quinta de Bolívar & 65 & 42 & 107 \\
\hline
\end{tabular}

Tabla 2. Lugares del centro histórico valorados como legado, valoración diferenciada por género.

Fuente: encuesta de la investigación. Los valores están normalizados, es decir el valor es relativo en relación al número de respuestas y encuestados por sexo.

Algo distinto ocurre en el estudio de caso en el norte de la ciudad, en donde las distintas indagaciones llevaron a señalar al humedal y los parques como los lugares más importantes, tanto desde la perspectiva de lo que se mostraría a un visitante como para enseñar a las nuevas generaciones. Resulta, además, ser el lugar señalado más importante en las prácticas cotidianas, un sitio para caminar, hacer deporte o simplemente para contemplar. Algunos elementos, como el Colegio Agustiniano, se consideran importantes pues sirven de punto de orientación, pero no se consideran importantes desde la perspectiva de un visitante, o para enseñar a un hijo. El valor arquitectónico del barrio Niza Sur se aprecia en especial para mostrar a un visitante. Es un patrimonio que no se valora como para ofrecer una referencia a las nuevas generaciones.

\section{Patrimonio vivido y patrimonio declarado}

La última dimensión de este análisis sobre la gestión del patrimonio y su localización en un contexto ampliado de la ciudad, y en un marco normativo como el POT de Bogotá ${ }^{11}$, alcanzamos algunos resultados interesantes en cuanto a la emergencia de un interés local. Aquellos residentes que están vinculados con el tema del patrimonio o con su defensa, han construido un saber más detallado y una preocupación más central hacia su conservación y formas de apropiación, reflejo de la construcción de sentido del lugar. En ambos casos, los residentes menos formados en los temas del patrimonio muestran mayor preocupación hacia otros aspectos, como la seguridad, y el lugar visto primordialmente desde su función como sitio de residencia.

\footnotetext{
${ }^{11}$ Plan de Ordenamiento Territorial (decreto 619 de 2000).
} 
La coincidencia entre lo que los residentes reconocen y la definición de bienes patrimoniales en el POT es cercana al 50\%. Las mujeres tienden por lo general a coincidir un poco más con la valoración oficial. En el humedal, esta coincidencia aumenta cuando se piensa la ciudad más allá del entorno inmediato sobre todo en los hombres quienes muestran una mayor coincidencia; en cambio, en el centro esta coincidencia disminuye si se piensa en el resto de la ciudad. El peso menor de los elementos declarados patrimonio se da en la valoración desde su importancia para las actividades cotidianas y va aumentando en la medida en que se piensa el lugar como un sitio para el turismo o la educación y promoción comunitaria.

\begin{tabular}{|l|l|l|l|}
\hline & Dimensión del patrimonio & Hombres & Mujeres \\
\hline 1 & $\begin{array}{l}\text { Peso entre los elementos valorados como } \\
\text { importantes }\end{array}$ & $54 \%$ & $55 \%$ \\
\hline 2 & Peso entre los elementos visitados & $36 \%$ & $38 \%$ \\
\hline 3 & $\begin{array}{l}\text { Peso entre los elementos valorados como } \\
\text { patrimonio para el resto de la ciudad }\end{array}$ & $31 \%$ & $31 \%$ \\
\hline
\end{tabular}

Tabla 3. Porcentaje de los elementos normados por los residentes (diferenciado por género) del centro histórico que coincide con el patrimonio declarado en el POT.

Fuente: encuesta de la investigación.

Es claro que en los dos casos, hay iniciativas concretas por parte de los residentes con disposición a participar en espacios y escenarios donde se les permita expresar sus opiniones y posiciones. Dichas opiniones, además, están construidas a partir de un conocimiento que tiene un nivel de especialidad, tanto por la experiencia como por el desarrollo de intereses específicos.

\begin{tabular}{|l|l|l|l|}
\hline & Dimensión del patrimonio & Hombres & Mujeres \\
\hline 1 & $\begin{array}{l}\text { Peso entre los elementos valorados como } \\
\text { importantes }\end{array}$ & $30 \%$ & $37 \%$ \\
\hline 2 & Peso de los elementos visitados & $24 \%$ & $32 \%$ \\
\hline 3 & $\begin{array}{l}\text { Peso entre los elementos valorados como } \\
\text { patrimonio para el resto de la ciudad }\end{array}$ & $56 \%$ & $26 \%$ \\
\hline
\end{tabular}

Tabla 4. Porcentaje de los elementos normalizados por los residentes (diferenciado por género) vecinos del humedal Córdoba que coincide con el patrimonio declarado en el POT.

Fuente: encuesta de la investigación.

Los residentes son fluidos en los procesos de revalorar el patrimonio, en tanto que sujetos individuales que están vinculados a distintas redes intersubjetivas y a la vez son nodos de recepción de valores colectivos. De esta manera, incorporan aspectos locales y emergentes como las nuevas bibliotecas y espacios públicos, valoran el 
saber y los oficios de las personas como patrimonio, se apropian de la naturaleza como un bien común con valor patrimonial, e incluso llegan a hablar del patrimonio vivo. Este discurso no coincide con el oficial que mantiene una posición más materialista y monumental del patrimonio.

Desde cualquier lugar de la ciudad, el centro histórico y sus cerros aledaños ocupan un lugar central en la patrimonialización. También se ha visto que hay una serie de elementos de reciente aparición en el paisaje de la ciudad, como el Parque Simón Bolívar o la Biblioteca Virgilio Barco, que se consideran patrimonio tanto por parte de los residentes del centro como del norte de la ciudad. Sin duda, los medios han contribuido a acelerar el proceso mediante el cual los elementos urbanos se van patrimonializando. Otros elementos emergentes, como el barrio Niza Sur, no son reconocidos de manera generalizada por sus residentes como elementos patrimoniales, y menos aún por los del centro. En el caso de los humedales, hay una valoración positiva a nivel local que no es compartida con los residentes del centro y a su vez, los residentes de la zona de Córdoba no le confieren un valor patrimonial a los otros humedales de la ciudad.

Los lugares-patrimonio son lugares vividos por sus residentes y desde esta perspectiva, ellos formulan propuestas amplias en cuanto a la gestión de su entorno. Los residentes, por lo general, son conservadores; es decir, prefieren las acciones de conservación, restauración y recuperación no sólo de los aspectos construidos sino también de las prácticas. En el caso del humedal de Córdoba, existe un claro consenso sobre la necesidad de conservar el humedal, y los residentes están de acuerdo en que no desean la construcción de nuevos centros comerciales en su entorno, que prefieren mantener su vocación como área residencial. Después, hay una serie de acciones en las cuales la población no muestra un acuerdo, como en el tema de la ampliación de la malla vial, los procesos de urbanización o la construcción de ciclorutas.

En cuanto a la gestión del patrimonio, las mujeres proponen acciones directas con los pobladores y acciones concertadas haciendo énfasis sobre la educación, mientras los hombres enfatizan el cumplimiento de las normas, la necesidad de informar y la acción institucional. En el centro histórico hay coincidencia entre hombres y mujeres frente a casi todas las propuestas. En cuanto al centro comercial moderno y a la reconversión de la Avenida Jiménez en oficinas, hay una mayoría de hombres y mujeres que están en desacuerdo. Es decir, que las propuestas de renovación y modernización aún no están claramente aceptadas por los residentes del centro. Sin embargo, hay mayor aceptación sobre temas como la 
recuperación de los cerros para la ciudad, aumento de la oferta educativa y la peatonalización. Alrededor de la conservación del patrimonio natural los residentes muestran un mayor acuerdo, mientras en las intervenciones urbanas hay mayores disensos.

\section{A manera de conclusión: heterogeneidad, un contrapunto entre residentes, sus prácticas, sus valoraciones y el punto de vista oficial}

Cada lugar patrimonio posee unas funciones distintas: el centro se ha configurado a partir de una variedad de funciones político-administrativas, comerciales, religiosas, culturales, turísticas, residenciales, mientras en la zona del humedal de Córdoba predomina la función residencial y la comercial. Se puede afirmar que la función de centro político-administrativo no parece tener hoy un peso muy importante para los residentes del centro histórico, al igual que lo comercial se valora en tanto que práctica social pero no a partir de su valor simbólico. Por el contrario, en la zona del humedal de Córdoba la función comercial tiene un peso importante en la valoración simbólica y de uso para sus residentes.

Encontramos una importante heterogeneidad de desarrollos locales en torno a la valoración y usos del patrimonio. La afiliación de los residentes de un mismo lugar a sitios, elementos y prácticas distintas, con intensidades diferentes tanto en la valoración como en el uso, permite desarrollar un análisis y una visión de conjunto de la configuración de los lugares mucho más rica que tratar los datos desde una perspectiva meramente estadística sobre frecuencias de visita o un sondeo de opinión sobre su valor.

Las centralidades y conectividad de los lugares mediante las interacciones de sus residentes, son una forma de ver las propiedades relacionales tanto sociales como socio-espaciales, evidenciando precisamente el patrimonio vivido y valorado localmente por sus propios habitantes. Ver el patrimonio desde una perspectiva relacional sin lugar a dudas da una información muy valiosa para defender puntos de vista en las políticas públicas que muchas veces son invisibles para los tomadores de decisiones.

La revisión de los datos desde una perspectiva de género, muestra que no existen diferencias marcadas entre lugares por género, es decir lugares o elementos estrictamente femeninos o masculinos. En ese sentido, se puede señalar que los espacios y prácticas más valorados son compartidos por hombres y mujeres. Algunos pocos elementos sí aparecen valorados exclusivamente por uno de los géneros. En esta perspectiva, se puede nombrar un comercio más masculino: los 
almacenes de 'eléctricos', los cines rojos, los concesionarios de automóviles, los bares y billares, así como casinos; o un comercio más femenino, como los almacenes de hilos y botones. En ninguno de los casos se trata de una valoración generalizada.

Sin embargo, es notoria la mayor sensibilidad de las mujeres frente a los elementos naturales, como cerros, humedal y parques, cuestión que aparece en todas las dimensiones del patrimonio que se exploraron. Esta sensibilidad se expresa además en la alta valoración que ellas confieren a los seres vivos que se encuentran en esos espacios, especialmente en el humedal de Córdoba. Los hombres, a su vez, muestran una mayor sensibilidad frente a los elementos arquitectónicos.

La ubicación espacial, es decir, la mayor cercanía a los elementos considerados patrimonio, varía la valoración que se hace de ellos. En especial, en el humedal de Córdoba se observa una clara relación entre la valoración y la preeminencia que ocupa en las prácticas cotidianas de los residentes y su distancia respecto a él. Hay una serie de lugares cercanos a la residencia que se valoran mucho para los que habitan cerca, como ciertos parques o iglesias, que tal vez se pueden considerar patrimonio barrial antes que para la zona. Pareciera que, en general, se puede decir que a menor distancia, mayor el vínculo que se establece con el lugar.

En el centro se detectó esta misma relación entre distancia de los lugares a la vivienda y su valoración, en especial en las actividades cotidianas, aunque menos marcada entre el uso que hacen los residentes de la zona definida como céntrica y aquellos ubicados en la zona periférica.

Para concluir, adherimos a las afirmaciones de García Canclini en cuanto al patrimonio cultural. En este estudio, se muestra que el patrimonio conserva una articulación importante con los discursos hegemónicos, que juegan un papel relevante en la valoración por parte de los residentes de sus lugares patrimonio. Pero también podemos ver que emergen discursos nuevos que están estrechamente relacionados con las prácticas cotidianas y sus dinámicas locales: se usa, luego se valora. Estos discursos emergentes están relacionados principalmente con los elementos naturales del entorno, para los cuales hay un alto consenso entre los residentes respecto a su valor simbólico y de uso, y por lo tanto también en las propuestas de gestión local. Esto sugiere que el patrimonio natural es una categoría que permitiría el desarrollo de procesos participativos de gestión de los lugares patrimonio, como un elemento catalizador de intereses comunes donde las mujeres 
podrían jugar un papel central, puesto que ellas son quienes han incorporado y movilizado con mayor fuerza este discurso.

\section{Bibliografía}

Borgatti, S.P.; Everett, M.G. y Freeman, L.C. (2002). Ucinet for Windows: Software for Social Network Analysis. Harvard Analytic Technologies.

Canales, A.; Canales M. (1999). "Grupos de Discusión". En Métodos y técnicas cualitativas de investigación en ciencias sociales. Coordinadores, Juan Manuel Delgado y Juan Gutiérrez. Madrid. Editorial Síntesis. Pp. 288-311.

Chaparro, J. (2006). “Construcción territorial del patrimonio en Bogotá: El centro histórico y el humedal de Córdoba". En Construcción de Lugares-Patrimonio. El Centro Histórico y el humedal de Córdoba en Bogotá. Editoras Adriana Parias y Dolly Cristina Palacio. Bogotá. Universidad Externado de Colombia - COLCIENCIAS. Págs. $173-236$.

Forni, Pablo; Marcelo Siles y Lucrecia Barreiro (2004). “¿Qué es el Capital Social, cómo Analizarlo en contextos de Exclusión Social y Pobreza?," JSRI Research Report \#35, The Julian Samora Research Institute, Michigan State University, East Lansing, Michigan.

Garavito, L. (2006). "Referentes legales sobre el patrimonio cultural en Colombia y Bogotá D.C. Políticas Públicas en el contexto de la relación cultura-naturaleza". En Construcción de Lugares-Patrimonio. El Centro Histórico y el humedal de Córdoba en Bogotá. Editoras Adriana Parias y Dolly Cristina Palacio. Bogotá. Universidad Externado de Colombia - COLCIENCIAS. Págs. 237-264.

García Canclini, Néstor (1997). Imaginarios urbanos. Buenos Aires: Editorial Universitaria de Buenos Aires.

Gross, J. D. (1996) 'Introducción to focus Groups'. En Area 28.2, 113-114.

Grudens-Schuck, N.; B. L. Allen y K. Larson (1999). "Brief Mythology of Focus Groups". En Ethnographer's Tool Kit. Schensul, J.J y M.D-LeCompte, Ed. Walnut Creek, Califo: Altamira Press.

Hanneman, R. A. (2001) "Centralidad y Poder". Introducción a los Métodos Del Análisis de Redes Sociales. Departamento de Sociología de la Universidad de California. <http://wizard.ucr.edu/ rhannema/networks/text/textindex.html>.

Massey, D. (1997) "A Global Sense of Place". En Reading Human Geography. The poetics and Politics of Inquiry. Ed. Trevor Barnes y Derek Gregory. London. Arnold. Pp. 315-323.

McDowell, L. (1999) Gender, Identity And Place. Understanding Feminst Geographies. Cambridge: Polity Press.

Palacio, D. (2006a), "Chucuas Bogotensis y sus vecinos urbanos: emergencia de una conciencia ecológica participativa". En Bosques urbanos en América Latina. Usos, funciones y representaciones. Ed. Sylvie Nail. Bogotá. Universidad Externado de Colombia. pp. 263-304. 
Palacio, D (2006b). "Redes y narrativas del patrimonio cultural y natural en Bogota. Un Analisis crítico de la gestión y la planeación participativa". En Construcción de Lugares-Patrimonio. El Centro Histórico y el humedal de Córdoba en Bogotá. Editoras Adriana Parias y Dolly Cristina Palacio. Bogotá. Universidad Externado de Colombia - COLCIENCIAS. Págs. 431-477.

Palacio, D., Hurtado, H., y Garavito, L. (2003). “Redes Socioambientales en tensión: el caso de la gestión ambiental de los humedales de Bogotá". En Redes. Revista Hispana para el análisis de redes sociales. Vol. 4 No. 6. junio-julio <http://revista-rediris.es>.

Palacio, D. (2002). “El parque nacional Utría, un Lugar-Red. Una propuesta de análisis socioambiental para la gestión de Áreas Protegidas". En Territorios. Revista de Estudios Regionales y Urbanos. No. 8, Págs. 39-61

Parias, A. (2006). "Representaciones de la Ciudad y trayectoria de los precios del espacio residencial en el Centro histórico de Bogotá, 1930-2005". En Construcción de Lugares-Patrimonio. El Centro Histórico y el humedal de Córdoba en Bogotá. Editoras Adriana Parias y Dolly Cristina Palacio. Bogotá. Universidad Externado de Colombia - COLCIENCIAS. Págs. 25-84.

Tello, S. (2002). "Introducción patrimonio e interdisciplinariedad". En En torno al patrimonio y la interdisciplinariedad. Universidad de San Martín de Porres. Perú. Pp. 5-16.

Thrift, N. (1997). "On The Determination of Social Action in space and time". En Reading Human Geography. The Poetics and Politics on Enquiry. Trevor Barnes y Derek Gregory (Ed). London. Pp. 376-406.

Van der hammen, M. C. (2006). "Patrimonio natural y cultural: visiones y vivencias desde la cotidianidad". En Construcción de Lugares-Patrimonio. El Centro Histórico y el humedal de Córdoba en Bogotá. Editoras Adriana Parias y Dolly Cristina Palacio. Bogotá. Universidad Externado de Colombia - COLCIENCIAS. Págs. 125172.

Van der Hammen, M.C y Palacio, D. (2006). "Género y capital cultural en lugarespatrimonio. Usos, representaciones y prácticas residenciales del Centro histórico y del humedal Córdoba en Bogotá". En Construcción de Lugares-Patrimonio. El Centro Histórico y el humedal de Córdoba en Bogotá. Editoras Adriana Parias y Dolly Cristina Palacio. Bogotá. Universidad Externado de Colombia - COLCIENCIAS. Págs. 265-332.

Wasserman, S. \& Faust, K. (1994) Social Network Analysis. Methods and Application. Structural Analysis in the social sciences No. 8. Cambridge: Cambridge University Press. 